Article

\title{
Effective Communication Processes for Building Design, Construction, and Management
}

\author{
Karen Boujaoudeh Khoury \\ Architecture Department, Notre Dame University, Zouk Mosbeh 72, Lebanon; kaboujaoudeh@ndu.edu.lb; \\ Tel.: +9619218950
}

Received: 26 March 2019; Accepted: 26 April 2019; Published: 5 May 2019

\begin{abstract}
Communication in architecture requires the participation of several individuals that share information, tasks, and resources. With new means of communication, the changes that have affected the construction industry in the last decade revealed new organization structure in practice. As many studies point out, the issue of IT integration in the means of communication, and the development of new organization models in the construction industry; however, an adjustable process model of mechanism enhancing project productivity, through effective communication, is not yet studied. Therefore, the study will explore the facilitators for better communication that will improve productivity in the architecture practice and make up an efficient communication model, which could be adapted by any architecture firm in Lebanon.
\end{abstract}

Keywords: communication; architecture; construction industry; facilitators

\section{Introduction}

Construction is a project-based industry. Projects are often behind schedule, over budget, and experience-poor in labor, supplies, and resources. This results in clashes and disagreements with the client and other involved parties. The beauty of the built surroundings is analyzed by the people living in the context and is being focused on in-press and publications. The problem arises from a lack of organization and from the request of old-fashioned ideas about the roles of experts in creating a flexible, approachable, and active construction team [1]. The problem arises from a lack of organization and the need for a better collaborative environment in architecture as a result of the complexity of architecture projects in-hand and of the increase in interrelated tasks assigned for the architect to deal with.

The objective of this research is to grant architects with facilitating elements that can maximize communication between participants in the design and construction phases in architecture projects. The factors and mechanisms leading to successful communication and enhancing productivity in architecture project management in Lebanon are examined in this research through seven case studies, covering $80 \%$ of the Lebanese construction industry. For quality architecture, the extracted principles are studied and summarized to be used in the structure of productive communication teams in design and construction.

\section{The Context}

Traditionally, design and construction were separate phases, which made communication between parties impossible. With the evolution of practice, jobs were accomplished either individually or collectively, as a firm, or even with joint ventures of international firms, with local ones. Thus, the process was not applied in the same way within the different structures of practice. Dubois and Gadde's study categorizes the industry into three main groups: "The tight couplings", "loose couplings," and "the collective adaptations". This is a result of changes in the design environment and the behavior of elements in this environment of work. Practitioners, researchers, and the social order at large 
have, consequently, called for a change in interrelations, behavior, and dealings in order to boost the probability of project success and improve end-results [2].

In today's fragmented society, construction all over the world is no longer produced by craftspeople. Formally, architecture stood for the way buildings were constructed, as well as for the materials and methods of construction. This process has been gradually displaced by the development of material science. Quality in construction is no longer judged by invention but rather the skills in implementation [3].

Therefore, communication processes are studied through the following means:

- $\quad$ The most appropriate use of information technology.

- The proper organization to be constituted.

- The roles of participants in the new value chain and the management of the whole process.

Examining what is already being used in the exchange of the know-how does not improve the situation; while discovering the facilitating factors composing the fundamental elements to form an efficient system of communication with IT integration, and which will result in a better system of work that may be adapted by every architectural firm in Lebanon.

\section{Literature Review}

Project management in architecture is the organization of activities performed in construction organizations that mainly deal with "planning, executing, coordinating, and controlling projects," resulting in new structures being built [4]. Unluckily, due to poor values in management practice, several construction projects do not meet their targets $[5,6]$. Consequently, the incentive for this research is the call for project success improvement in the construction region. Particularly, this work focuses on the role of communication in the success of a construction project [7-9].

Major mechanisms of communication process are trust and commitment between the project members $[10,11]$. Previous studies have shown that a communication system, based on trust and commitment encourages: Economic performance in terms of reduced cost overruns [12], time performance [13,14], quality and customer satisfaction [15], environmental performance [16,17], work environment [18,19], and innovation [20-24]. These examinations propose that communication structure may affect how procurement procedures influence project performance in a role, as an intermediary or as a moderator [25].

\subsection{The Change in the Design Environment}

The roles of design and engineering experts changed with the rapid change in design processes in the 1990's. Most of the time, architectural design was totally separated from systems design and engineering. Based on David Gann's study on the behavior of elements in the construction industry, two main reasons were behind this separation. The first reason is the implementation of new technologies in the construction of buildings, as a result of their complex structure; and therefore, more experts have to be involved in the process, making communication more difficult. Second, the use of information technology in design had a major impact on the way participants communicate together, thereby changing the traditional way of communication, which was based on oral and face-to-face coordination [26].

Therefore, the construction industry is highly fragmented, known for its low productivity, cost, time over-runs, and conflicts in delivery compared to other industries [27].

\subsection{The Complex Interaction of Participants}

The increase in the number of tasks, and their specialization, requires the need for many participants on site to construct the designed project, which may be measured as a precise provisional set of connections within a more 'permanent' network. In Figure 1, firms A, B, and C are all involved in construction projects. Their participation in each project is made up of resources of different kinds 
(A1, B1, and C1). The firms are also concerned in other projects in which they have to organize their activities and resources with various sets of other firms. For example, in Figure 1, firm C needs to consider four different dimensions of co-ordination: [28]

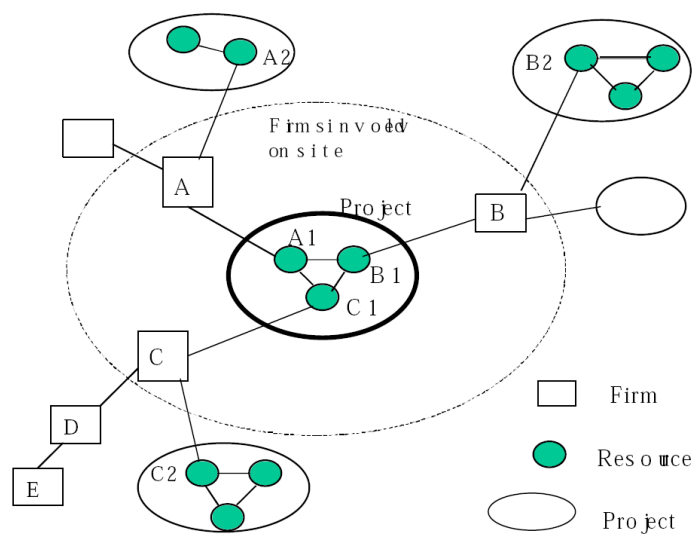

Figure 1. The construction project in its network context (Dubois and Gadde 2001).

-co-ordination within the single project (C1 with $\mathrm{A} 1$ and $\mathrm{B} 1)$

-co-ordination among firms involved in supply chains (i.e., with $\mathrm{D}$ and $\mathrm{E}$ )

-co-ordination among different construction projects ( $\mathrm{C} 1$ with $\mathrm{C} 2)$

-inter-firm co-ordination beyond the scope of the single project (i.e., with A and B).

Construction is characteristically a difficult multi-task process, accomplished in an uncontrollable environment within many manufacturing industries [29]. He has concluded that construction is mainly about synchronization of experts and distinguished tasks at the site level.

Architecture project management in Lebanon was affected by the European and American system of work, as the profession extended to become a multi-functional one. The formation of firms was developed and the role of the architect was limited to the design phase only; except for small firms where the architect used to be involved throughout the whole process.

\subsection{Lack of Communication}

The development of architecture firms started with the change in the design process that affected the profession around the world. The need for specialization required several members to work on the same project. Small firms, in which the architect was once responsible for the whole process, are no longer attracting the attention of clients interested in the modern system of interaction, between more than one expert in the field, and that had delivered better quality in the architecture. Nowadays, communication in the construction industry happens between the client, project manager, architect, executive and associate architects, consultant, and construction manager. Therefore, only examining the digital tools does not improve the situation. Communication patterns are studied through the following means:

- $\quad$ The use of information technology

- Team organization

Currently with the development of the architecture profession and its extended form of practice, the work of collectivity has become more complicated with the increase in intricacy of each project and the tension between the members involved in the process. The need for a system of communication is being discussed in large firms handling complex structures of communication in Lebanon.

\subsection{Communication Troubles}

Recognition of frequent problems practiced on past projects in their construction business environment is a superior opportunity. Based on the Asian proverb, "a problem well-defined is a 
problem half solved," project members must be practical in organizing their projects in which probable problems are fully expected [30].

Based on Tai, S. et al. [31] study, there are numerous reasons for communication troubles:

- Lack of fine communication means. Short of suitable mechanisms to motivate the members to communicate energetically is the main problem. The conflicts of awareness between the participants and the privileges and obligations of every party are clearly written in the contract, and this makes the most of its own interests and drives each member to maintain the information with no motivation to communicate. To avoid violations of its own benefits, each member leans to take care of information as "confidential" rather than "sharing". Thus, as the survey shows, each party is unwilling to interconnect their computer system or arrangement. In fact, through the use of advanced communication technologies to improve coordination; added value can be produced [31]. Because of the lack of "extra benefits" sharing device, the participants avoid active communication with the others.

- Fragile managerial structure of construction team. The usual form of construction team is a linear structure. There are a lot of middle-level employees from the owner at the top, to the lowest construction member of staff. Prior to reaching the planned recipients, communicated messages have to go through an extended and tortuous process of transformation. This leads to the deformation of information [32].

- Lack of consistent principles for construction information. As a project's size and the complexity of technology increase, construction projects frequently engage hundreds of professionals. Moreover, hundreds of firms may unite the construction team at different times. Organizations can have a different understanding and knowledge of the identical building projects, and similar construction information may have dissimilar forms of expression. A lack of consistent information standards across the entire industry is an additional barrier to communications [33].

- Lack of maintenance of highly developed communication technologies. As a labor-intensive industry with comparatively low levels of information, the request of new information technologies, compared with the manufacturing industry, has been delayed. Regardless of the introduction of computer technology in the building industry in the 1960s as limited component analysis and CAD, it is mostly used for the reason of generating information [34].

A very significant study is that the majority of the problems are human and organization related problems [35]. These troubles or unpleasant factors are integrated in a list of problems examined to determine the degree of their occurrence and influence on construction projects in Lebanon. For this reason, the study included questionnaires testing people's behavior and their impact on the communication structure.

Following the above-mentioned obstacles for project success, the study will develop the essential factors facilitating communication in terms of communication means, structure of construction team, and integration of information technology. It must be kept in mind that the technologies to shift and share construction information is increasing in the Lebanese construction industry.

A study of the literature outlines the major obstacles in communication, that are mainly found in human and organizational factors, which have been included in the research model and examined to find their effect on communication in projects.

Consequently, the research model will include the common success measuring variables from the different literature streams, to examine their effect on the communication linkages from which successful communication aspects are extracted. These variables are summarized as: Security, reliability, learning skills, and an integrated IT system. These factors are categorized under team organization and IT integration. 


\section{Team Organizational Factors}

The way a project team is structured can play a major role in how it functions. Different team styles will have different characteristics. Within a team, you will find a mixture of different people with different assignments, but that does not necessarily require a hierarchy. The best team cultures develop where team members recognize that everyone else also has an important value to contribute [36].

Figure 2 extracted from a study on collaborative teams reveals a diagonal selection of members belonging to a variety of positions enriching the communication process and making it more successful.

\section{Collaborative Teams}

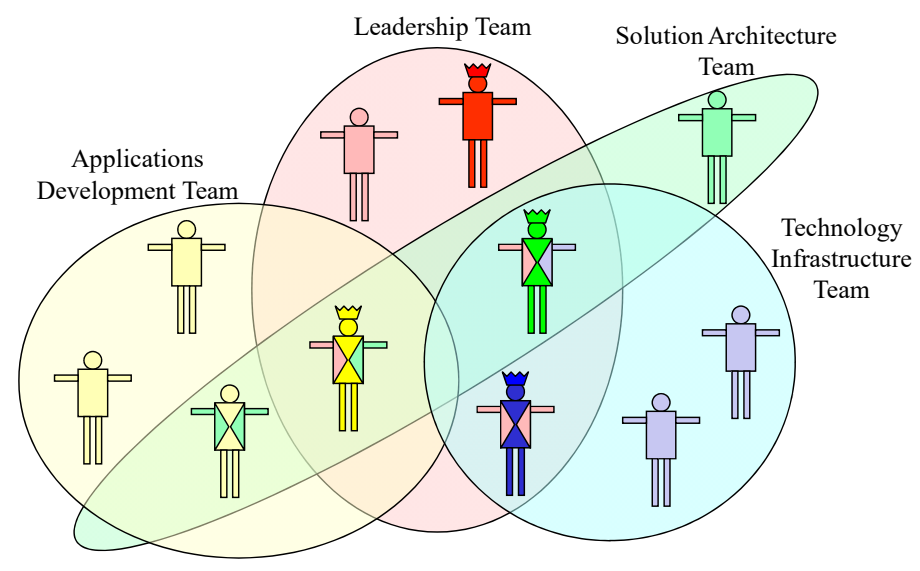

Figure 2. Collaborative teams [37].

The importance of team communication in the design of buildings is attracting the attention of many researchers, due to the increase in the complexity of the technical and organizational structure of any construction project [37].

Harmonizing team communication is "a team effort and it would appear that a bottom-up approach to the management of team communication is required to improve effectiveness. Developing a common understanding of effective communication in the team and using the most appropriate means for the purpose is a fundamental aspect of team performance. Team members have to experience the practical and effective use of new communication technologies in their daily work" as understood by [38].

The success of a team-based organization is related to the management systems and structures, which must be supportive of teamwork together with employee selection method, reimbursement, and incentive programs, performance evaluation procedures, teaching programs mainly with reference to team-skills, information organizations to meet the requirements of empowered teams, and scheduling and resource allocation systems [39].

The need to organize people is, therefore, a must when members increase and communication becomes more complicated. In [40] the authors provide, "in integrated project delivery, the architect and contractor work together, often as part of the same integrated firm. As a result, project communication and coordination often run more smoothly than in traditional project delivery, which separates designer and builder. This collaboration has many benefits for design and construction practitioners and their clients".

\section{IT Integration Factors}

Traditionally, for any architecture design project, design team members meet to watch a presentation, argue design issues, and from time to time, draft an initial design developed in detail by one or more team members after the meeting. Usually, these meetings happen around a conference table, but lately, technologies such as video teleconferencing, live board, fax, and computer mediated 
meeting spaces have made it feasible to hold meetings for synchronous collaboration among design team members who are geographically dispersed. The most basic efforts to maintain synchronous collaboration, in architectural design, employed video links between collaborating designers' offices.

The information flowing among members was highly affected by IT integration in the last decade. Because of the nature of architecture design practice, which is project-oriented, members are dependent in their relationships, which creates data dependency. Moreover, tasks overlap in practice, resulting in the exchange of data within the same time interval, which questions the nature of the technology or software used, which could be updated frequently and accessed by all those involved.

The use of computers and IT integration has changed the architects' world to a more complex one in which they are obliged to deal with several new factors, making them face new concepts, studies, and worries to solve. Architects, dealing with uncertainties, have to handle several independent tasks and collaborate between the experts working in each phase. The innovation of technological system of work include, the software used in the design drawings and the web-based systems, enabling each member to share his/her knowledge with every involved person. This IT integration in the architecture practice made the process easier, but it still needs a structure to follow, in order to achieve quality buildings, rather than just a project to deliver.

In reference to the development of Mitchell's four technologies, three observations have been added by Rahmawati, Y., N. Anwar, C. Utomo, about their valuable use in collaborative design. First, the boundary that a collaborative design arrangement presents to its users is a significant determinant of its achievement. Designers require wide and complicated computing experience; their efficiency will associate straightforwardly with the usability of the interface. Preferably, a collaborative design system is ought to present as simple an interface as the designer's familiar pencil and paper. Nevertheless, it must also make it easy for a designer to use the absolute capabilities that computer support can make available: Restrictions examination, concurrent and immediate work with other designers, iterative changes and versioning, filing and indexing. Since drawing remains the most important means of communication among designers, the discussion of synchronous collaborative work deals with drawing as a crossing point to collaborative design.

Second, designers create a lot of data as they work, and it is necessary to discover ways to capture, organize, and file this information, so that all members of a team can make use of it. For example, one participant's comments provides, "In the VDS project a mountain of files was generated by participants from different universities. It was a difficult task determining which and how some of these files related to each other. Which floor plan goes with which section or surface model?" The public area for team members to post their work is not enough. Designers call for a quick, easy, and in some cases, automatic construction of links and annotations between these postings that capture the relationships among the individual drawings, photographs, and comments that include the collaborative design document.

In conclusion, a design team must organize its efforts clearly: The efficient performance of a team requires designers to be in agreement and to work in definite ways. At a basic level, the team must settle on protocols for communication (turn-taking, scheduling, file formats). At the level of the design artifact, the team must have the same opinion about areas of design dependability-"who will make what decisions and what rules shall govern the decisions designers make?".

The purchase and exploitation of technology: The study survey shows that there is a great use of technology in the construction industry in Lebanon, but on the other hand, it reveals the aspect of refusal of innovation, where each member is responsible for an assigned job, rather than an innovative one within the technology.

Moreover, in the construction industry, using technology refers to the use of specific software. This integration shows that people need to communicate the technological strategies in the construction industry among the level of organization. Technical communication is highly affected by the IT system integrated and adapted especially in countries similar to Lebanon where technical support is considered weak. 


\section{Research Design}

\subsection{Data Collection Methods:}

Information was composed in a series of personal interviews conducted with various groups, including managers and employees, within the project group. Interviews collect field data for empirical modeling in order to select appropriate and related knowledge artifacts from the list of possible ones. Collecting data for experimental modeling requires the creation of a sample of projects, that symbolize the reality in the field of the study. The analysis targeted 20 main architecture firms in Lebanon from which 7 case studies were summarized.

Questionnaires were handed and addressed to project managers and participants involved in the process, to test the participants' behavior and formulate the existing models of communication. This questionnaire examines all the tensions that arise in the practice, and specifically the control over the point of transformation between the design and construction phase, and how the process is being achieved differently under variable systems of practice in the construction industry in Lebanon. The answers by the variable organization structures are analyzed to indicate the factors that facilitate communication and ensure a precise implementation of the design phase in the construction part.

To analyze the cause of flow of project knowledge in architecture firms, a qualitative case study approach was undertaken as a variety of actors, knowledge retention practices, access, and reclamation of data, and issues in sharing knowledge were recognized and analyzed.

The factors and variables extracted from the literature stream made up the questions in the respective questionnaire, including project scale, number of participants, and innovation in IT. The questions covered the effect of each factor on the success of the architecture project. Additional variables, such as the importance of people rather than organization, and the effect of internet connection on communication, were determined through personal observation and were added to the examined research model.

Figure 3 indicates the triangulation method in this qualitative research that was done to increase the credibility and validity of the results.

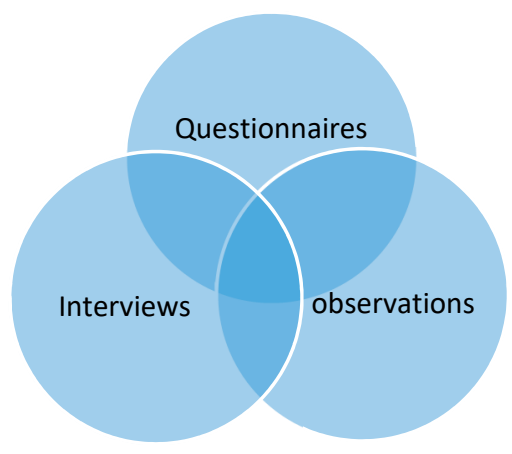

Figure 3. Triangulation model.

Questionnaire sample: see Appendix A.

\subsection{Case Study Analysis}

The analysis of each case study included: Project definition, case study topics, design architect's role, owner's role, project manager's role, consultants involvement, onsite supervision, team structure, cultural differences, project delivery system, use of information technology, information management, digital technology, and working at a distance.

In the following section, each proposition is tested in each case study to establish the facilitating factors leading to the success of the project in hand.

Figure 4 lists the variables influencing communication throughout the project phases in an architecture firm. These variables are examined afterwards in the data collection process. 


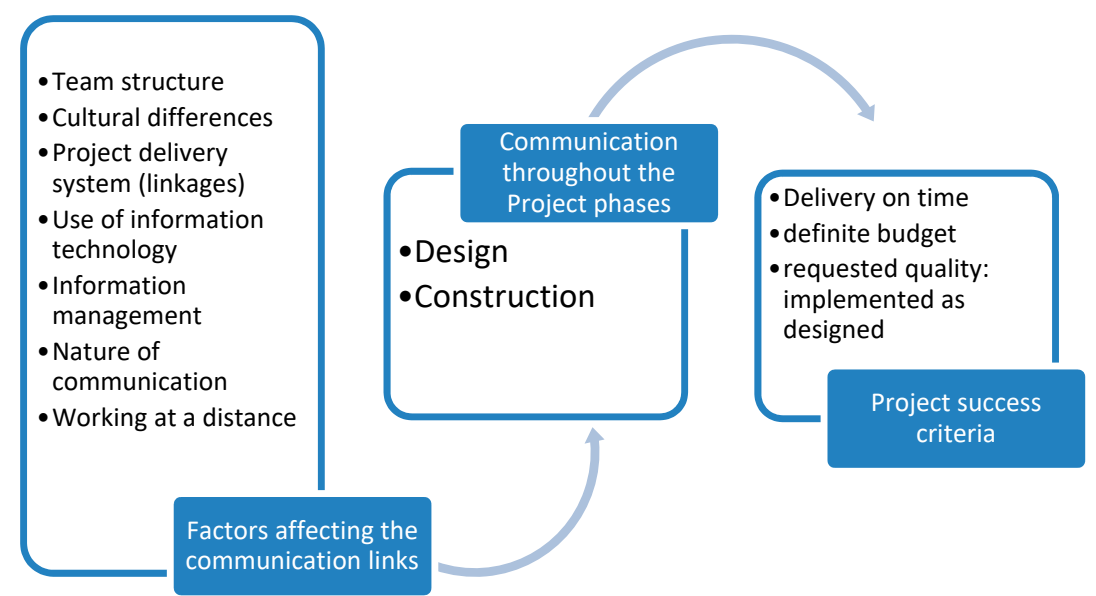

Figure 4. Research model: The value of factors influencing effective communication are examined in the data collection process.

The qualitative study covers the real observation of cases in architecture firms in Lebanon, with open ended questions addressed to the project managers and participants involved in the process, to test the participants' behavior and formulate the existing models of communication. This questionnaire examines the effect of all the variables on communication links in the construction industry in Lebanon. The answers by the variable organization structures are analyzed to indicate the factors that facilitate communication for successful project delivery.

Proposed hypothesis: The need for facilitating factors to improve communication and enhance productivity in architecture project management.

In each case study, the project delivery system and the communication pattern is derived where the factors affecting communication are indicated as facilitating or inhibiting.
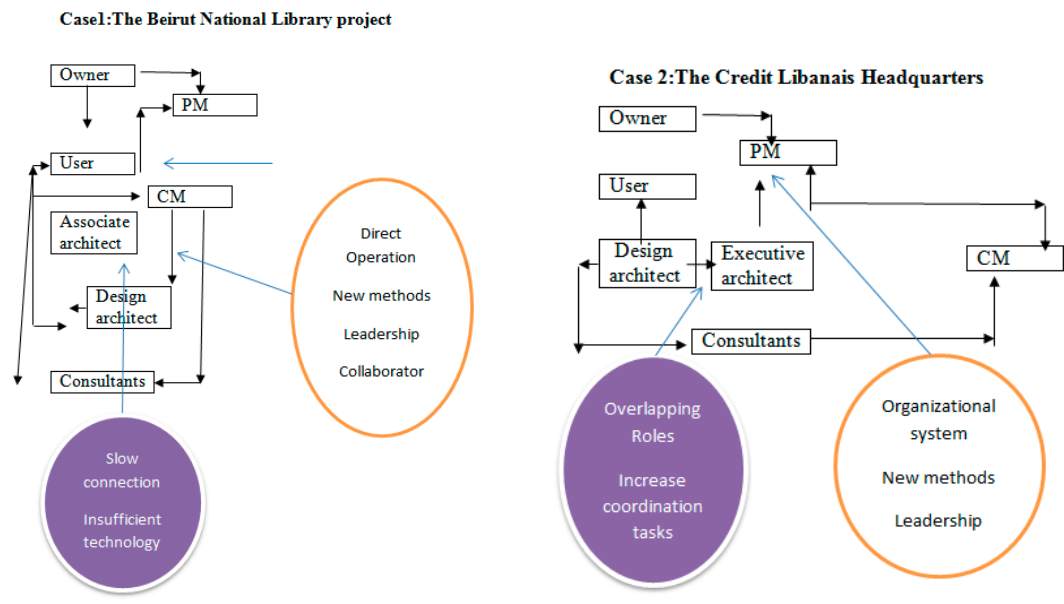

Reliability: Revealed in the coordination between the chief international project officer assigned by the engineering office in Qatar locally for design interference and control, and the representative of the Ministry of Culture.

Learning skills: Requested for the overall design consultations and solutions, in addition to the need of expertise in different fields.

Integrated IT system: IT usage facilitated communication between architecture and engineering teams and the parallel communication, between the design and construction phases presents a well-organized IT system of work in the construction field.

In Case studies 3 and 4, the project delivery systems show the importance of collaboration for problem solving. 
Security: The project design managers in the office had to compromise between several professionals for the need of expertise. They had to arrange the required collaboration tool to achieve the project's needs.

Reliability: The project manager had direct communication with all members on site, which made it easy for him to get involved in the implementation of the designed project on site. Furthermore, he was able to interfere in the need of expertise in parallel with the designed process.

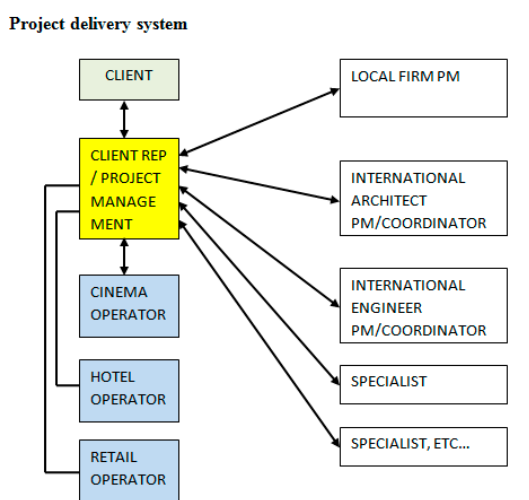

Weak IT integration: The client had to confirm and agree on each progress of design and implementation, but did not have any direct communication with any of the involved parties in both design and construction departments. This made it hard for the project to be developed and executed within the given timeframe, since it took a lot of time to get the approval from the client for each and every modification.

Learning skills: The team had to implement the designed plans on site without any contact with the design architect. This increased the misunderstandings of design drawings and resulted in the delay of the execution process.

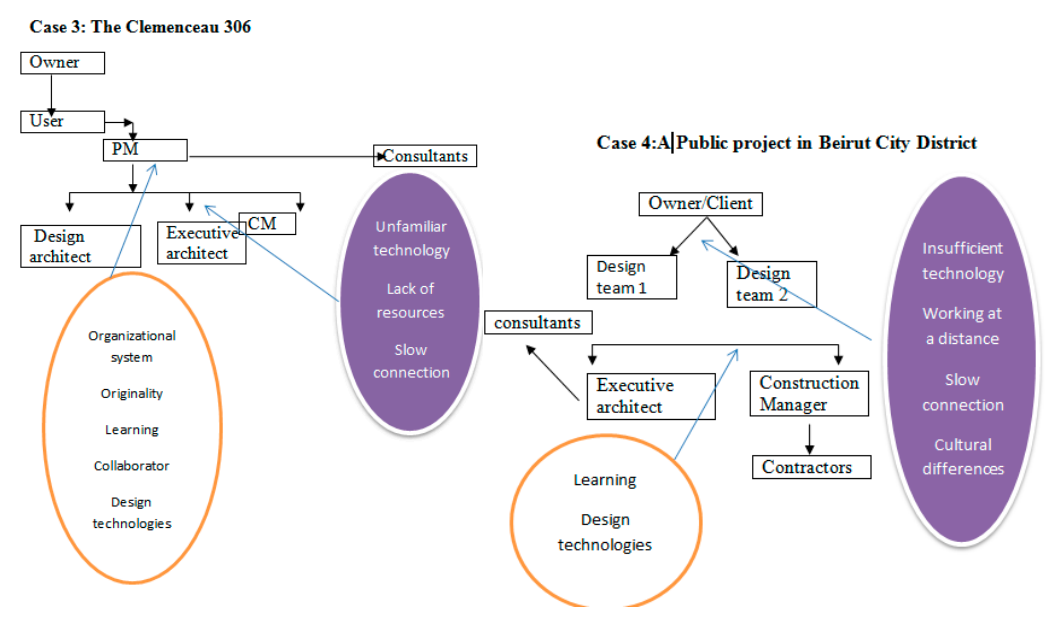

In case studies 5, 6, and 7, the project delivery systems reflect the smooth communication between participants and the success of the project, although the exchange of documents from different geographical locations was not easy. 


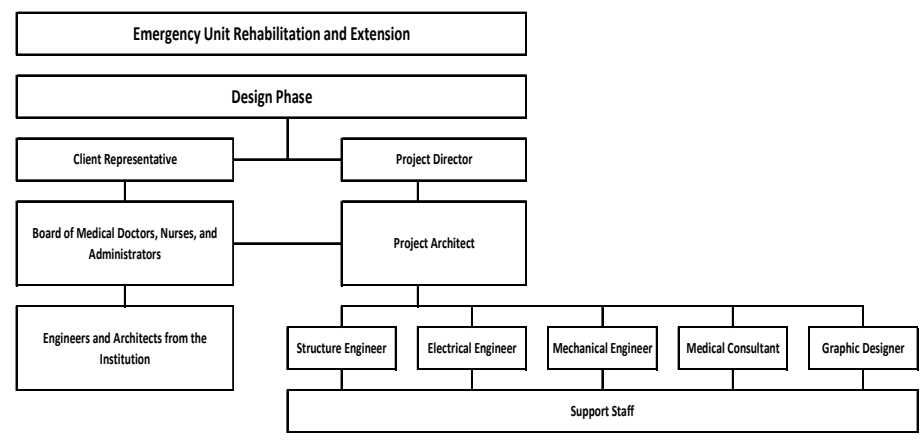

Security: The design architects located abroad had direct relation with the executive and sub consultants in Lebanon. The communication was straight either F2F or by email. The design team had the final decision for any design modifications.

The client had to approve the final step before execution. The needed experts were contacted in Lebanon by different technological systems.
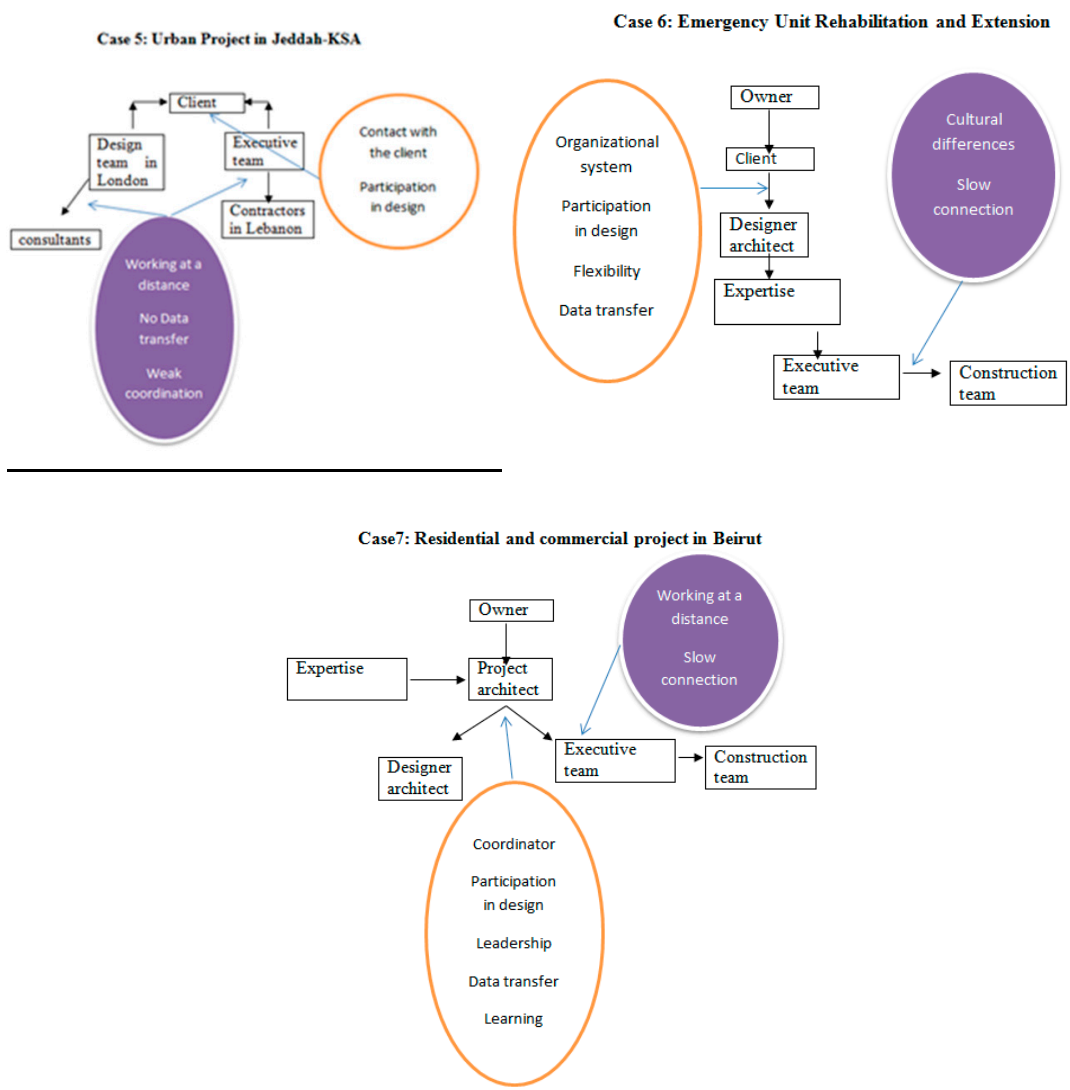

Reliability: The cultural differences revealed in this project did not affect the project delivery process. Each did his/her job irrespective from their background or cultural beliefs.

However, the Lebanese consultant team had to meet the client once in Jeddah, but for cultural reasons and restrictions, they were not allowed to enter the country because they were females.

Therefore, the design team in London had to present themselves as the owners of the project instead of the Lebanese consultant team. From then on, the communication was done by email, fax, and many other technological systems. 


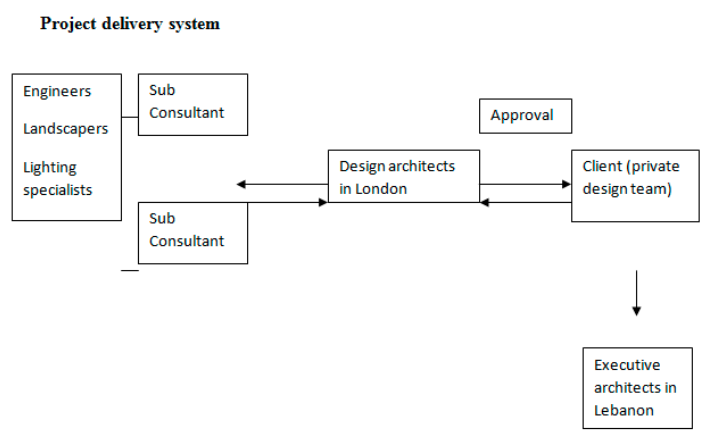

Integrated IT system: This case followed a linear structure in the relation of participants. However, each member in the process had to refer to the design architects in London to take approval from the client in Jeddah. The impact of technology on communication between participants scored high because of the geographical boundaries.

Learning skills: The client was the one to approve the designed plans and call for execution because of the need of expertise.

\subsection{The Results Are Summarized in the Below Figure:}

Figure 5 indicates the major factors affecting communication in a team structure.

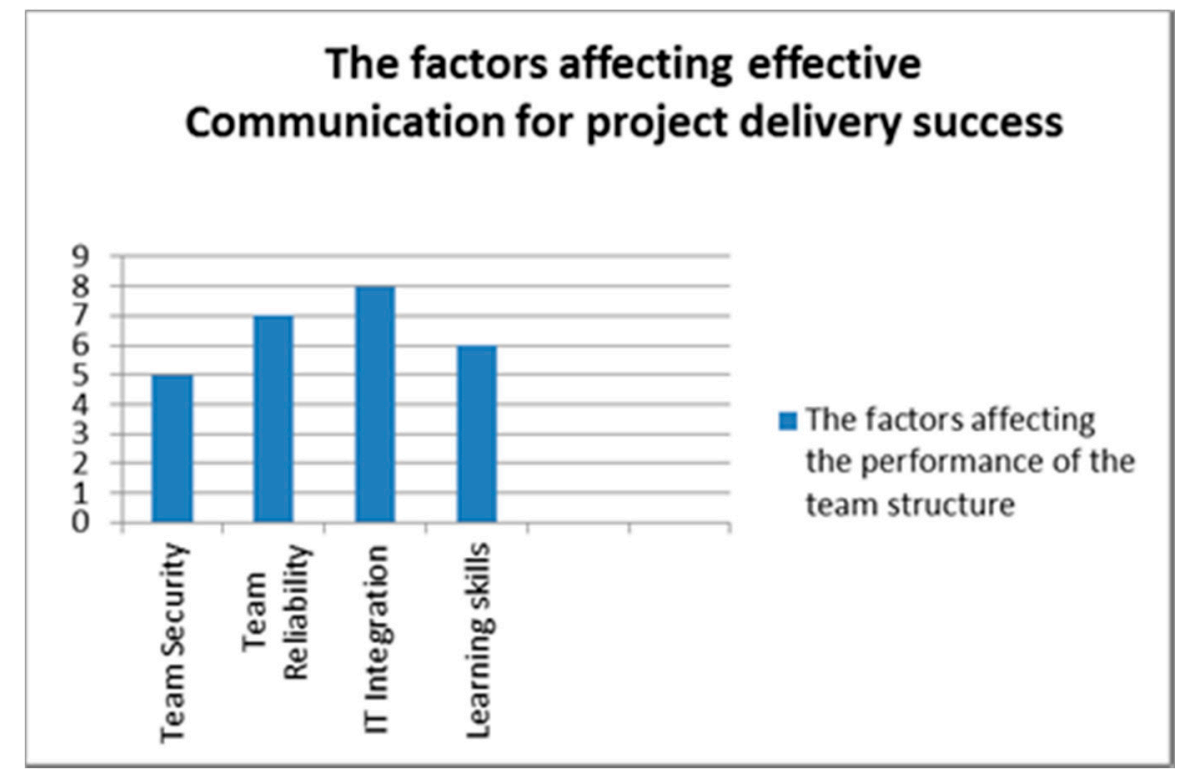

Figure 5. Factors affecting communication in a team structure.

In the case studies, the description of facilitators and inhibitors was made in relation to the communication system. The outcome of these principle elements is recomposed to describe the successful elements of collaboration in terms of organizational system and information technology.

\section{The Characteristic Categories of Communication Are Summarized as Follows:}

The standards of both facilitators and inhibitors are summed up in order to illustrate the levels of impact in a qualitative method. The values, which do not stand for statistically precise weights, are based on the interpretations of the concerned members in the projects chosen for the case studies. Nevertheless, for this qualitative analysis, this kind helps readers recognize the effect of each factor and its impact on the collaborative design project (Table 1). 
Table 1. Categories of communication.

\begin{tabular}{cl}
\hline In Terms of Team Organization & In Terms of Information Technology \\
\hline 1- Team structure & 1- Electronic data transfer \\
\hline 2- Innovation & 2- Design technology \\
\hline 3- Learning curve & 3- IT for working at a distance (geographical boundaries) \\
\hline
\end{tabular}

Each factor had a different impact on facilitating or inhibiting communication. The values received from the conducted survey are recorded in the below Table 2.

Table 2. The value of major factors (participant-related) facilitating communication.

\begin{tabular}{|c|c|c|c|c|c|c|c|}
\hline 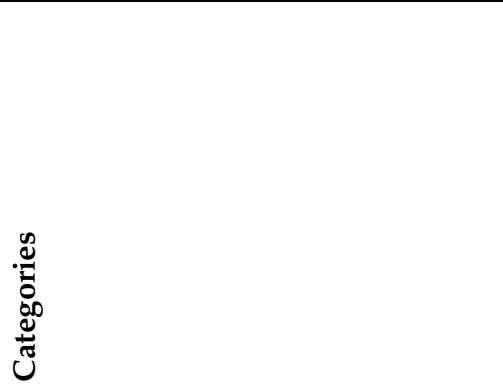 & 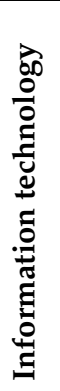 & 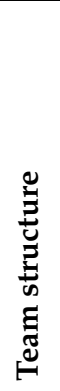 & 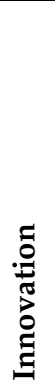 & $\frac{0}{2}$ & 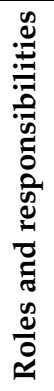 & 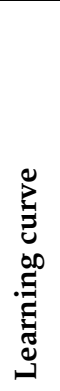 & 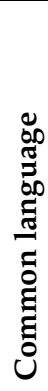 \\
\hline Team organization-facilitators & 2 & 4 & 7 & 4 & 5 & 7 & 2 \\
\hline Information technology-facilitators & 6 & 2 & 4 & 3 & 1 & 2 & 1 \\
\hline Team organization-inhibitors & 2 & 4 & & 3 & 3 & 2 & \\
\hline Information technology-inhibitors & 5 & 2 & & 1 & & 1 & 1 \\
\hline Summation of values & 15 & 12 & 11 & 11 & 9 & 12 & 4 \\
\hline
\end{tabular}

\subsection{P1: The Impact of Team Structure on Communication Links}

Proposition 1: The impact of team structure on communication links determined the participant's role in successful communication. This did not vary, whether the firm had local or international links. In either case, the factor had a high impact on the communication links, leading to the success of the architecture project and stresses on the importance of people rather than organizations.

\subsection{P2: The Impact of the Use of IT on Communication Links}

Proposition 2: The impact of information technology on communication links was found to be essential for a successful communication, but it was not valued in local projects, which had no international links. It highlighted the importance of IT skills, learning curve, and innovation that were considered new variables to be included in the study.

\subsection{P3: The Impact of Information Management on Communication Links}

Proposition 3: The impact of information management on communication links and the assignment and organization of tasks to participants, to deliver a project on time and have a smooth communication structure between members, are considered basic in a successful communication system. This factor had a significant effect on the success of the architecture projects, whether on local or international connections.

The following listed table analyzes the participants' effect on the variables and determines the importance of people in the organization. 


\subsection{P4: The Impact of Project Delivery System on Communication Links}

Proposition 4: The impact of project delivery system on communication links was delivered by all firms according to the organization of tasks related to each project. The models presented a common structure that enhances communication between participants. This happens to be the hierarchal structure, the most effective one in architecture firms in Lebanon. It focuses on the importance of people and team structure.

\subsection{P5: The Impact of Working at a Distance on Communication Links}

Proposition 5: The impact of working at a distance on communication links, categorized under the geographical boundaries, affected the firms with international connections greatly and had a high negative impact on the success of the project. Moreover, the success of any project happened to be highly affected by the geographical boundaries, since it might lead to the project's failure if its communication has been interrupted.

\section{Major Contributions}

The factors and mechanisms that can improve each factor and thus maximize the communication efforts are determined by:

\subsection{Information Technology and its Appropriate Usage}

The previous research on information technology, its integration in the construction industry, and usage and effect on communication, have revealed a positive impact on its importance of the success of a project in the construction industry. However, information technology was found inefficient without the existence of two distinct factors, which facilitated the usage of information technology.

The efficient use of information technology depends highly on the participants who use it and the geographic boundaries that are minimized by information technology, consequently improving communication.

Therefore, the minimum required skills in information technology, necessary for architects, and the techniques and tools that architects and project managers use to track distance communication, are examined and discussed in this section.

Information technology has been essential in the exchange of data between participants working on both the design and construction phases. Email was basically used for communication and the files and attachment exchange. Although, some parties still prefer fax during design phase, because sketches and markups can be sent easily. Extranets were rarely used in the design phase, except for the case studies 1 and 2 where the client and other important participants who were geographically separated had to be informed by every modified part of the design and approve it before continuing the work.

\subsubsection{Eliminating Geographic Barriers: Boundary-Less Communication}

The case studies analysis covered the current means of communication using information technology in each firm for distance collaboration. The listed tools and features help minimizing geographical boundaries.

Intranet

The intranet functions as an information management tool, which facilitates boundary-less data sharing, rather than just a communication device. Using this tool, participants refer to design standards and construction manuals, which were made available in paper form and CD-ROMs before. In case number 4, the public project in Beirut city district, involved members were not able to communicate easily within the same firm. Problems in the system affected the exchange of know-how and consequently delayed the project's time frame. 


\section{Extranet}

Extranet is rarely used by architects on their own initiative. In this research, extranet was found to be less important than any other device in improving communication between members in the design phase. It was only vital for architects in the construction phase where the designer was able to track the implementation of the project on site without visiting the site personally. The updated files informed the architect from his office with all the modifications and changes that happened on site. This is quite clear in case study 6, where the architect and the client, located at a distance from the construction site, were able to interfere and get all the modifications on time.

Ftp

Distance collaboration projects such as case studies $1,2,4$, and 5 used ftp sites to exchange, not only digital drawings and data, but also scanned sketches and images. This made it easier to approve each detail with less time and respect the given time frame.

Email

Email has significantly changed the work at a distance in the construction industry. It made the work between firms located geographically apart an easy job. It is mainly used in all case studies, whether the client lived locally or abroad, and whether two or more firms were involved in the same project.

Email made the exchange of data, drawings, files, information, modifications and much other important knowledge easily delivered and used.

On the other hand, some emails had a negative impact on the project if the content was not clear enough to be understood by other participants. In this case, many designers prefer fax for sending sketches and explain them directly.

\section{Video Conferencing}

The cost of video conferencing was the main obstacle in using it; instead phone conferencing has been used to make group discussions and consequently were more effective.

Even though information technology has been marked as a vital feature for the success of the project in the construction industry, human factors are still found to be important in improving communication at a distance. There is an agreement between interviewees that information technology (IT) can help to develop data exchange; both communication and interaction within the project team and within the project delivery chain. IT is frequently connected with enhanced organizational flexibility, faster admission to information, fast responses to varying conditions, better innovation, and improved decision making.

\subsection{Building the Team}

Team-building is significant for the successful achievement of any project. The purpose of the team is to deliver a project completed on time, is on or below budget, is cost-effective to all team members, with no claims, and consequences in a pleased owner. Challenge, certification battles, doing hazardous actions out of spite, and other disturbing actions may result in at least an unpleasant work atmosphere and more likely an unproductive project.

The construction team is frequently considered as including the architect or engineer (design team), owner (client's representative), and freelancer (builder). The design team is composed of architects, engineers, and consultants that create the construction plans for the client who could be a public or private unit presenting the project necessities and financial support for design and construction. The outworker typically builds an exclusive project in a very aggressive setting. Other members affecting a project team are public involvement and governmental regulators. 


\subsubsection{Teamwork}

Teamwork is known as a "cooperative effort by the members of a group or team to achieve a common goal" (Webster's 1984). The case studies identify successful team members' practices that can be used to generate an improved cooperative endeavor between the project team members or teambuilding members in the construction industry.

Teambuilding engages definite tasks that are usually a division of the construction process, but they are accomplished with the purpose to generate a team. The objectives of these activities are to promote communications, support coordination, and cooperation, keep away from possible problems and disputes, and maintain high morale.

Team-building requires a firm effort on somebody's part; this is usually done by the client delegate or a construction manager (CM). The owner's representative or CM naturally hold construction contracting knowledge and their background is either, from the design professional's or builder's point of view.

\subsubsection{Team Communications}

Unsuccessful communication, which equally lowers efficiency, and loss of time and money, can create excessive stress and pressure between team members. Efficient teams work during breakdowns in collaboration, by raising and promoting open and clear communication among team members. The three key fundamentals to successful project communication are, significance, awareness, and happening. Appropriate communication is alert to the point and task-oriented. Approachable communication engages the enthusiasm to collect information from others, dynamic listening, and building on thoughts and views from others. Occurrence is recognized communication ways and timely reactions. Postponed upon desired communication, within team members, can only cause matters to irritate and lead to a collapse of the team and its performance.

Communication among team members has never been so simple and fast. Email, cell phones, the internet, and extranet permit projects to be organized 24 hours, 7 days a week. Several cautions come via these innovative technologies that tolerate immediate communications. With the failure of personal contact, we mislay the capability to watch and ensure the sender's verbal communication. Electronic mail can be quickly written and can communicate incorrect purposes, when insufficient time is permitted for the sender or receiver to examine the communications or problem in a complete point of view. Email can be rapidly forwarded to others without the senders' awareness, so make sure what you write down is projected for anyone's eyes. It is significant that you consider first, and make sure you are not expressive over the issue, and it is suggested that any issues are clarified by calling first ahead of writing.

\subsubsection{Organizational Structure}

Figure 6 shows the interaction of entities involved in a project process and their usage of information technology. Section 5 in this research has studied the relation between the involved members with the design team structuring for each case study in which the owner and the architect grasp the advantages and disadvantages of each system.

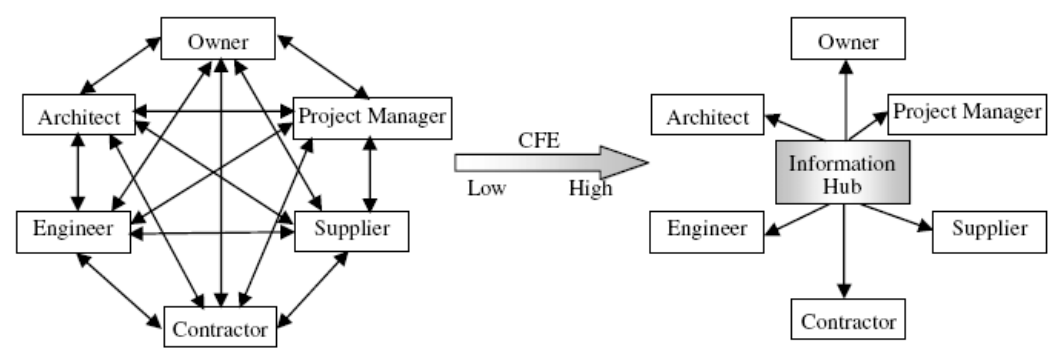

Figure 6. X.Xue et al International Journal of project management 25 (2207) 150-157. 


\subsection{Improve Communication through Innovation: Client's Innovation Along with the Designer's Innovation}

One of the major issues is having innovative ideas and the most important thing is the acceptance of new ideas. If one of the participants comes up with a new feature that solves the problematic situation, the other members should learn how to understand and accept new technologies and ideas.

Basically, people do not have the ability to imagine how they can build the building at the beginning, but essentially, it was found throughout the case studies that, it is a learning curve. In each case study, different approaches have been made to make the final image of the project clear to all parties involved.

Figure 7 Demonstrates communication within the influencing factors. An appropriate usage of IT, a good grasp of the knowledge of a well-structured project delivery system and an organized team structure, and the elimination of geographical boundaries can all promote better communication, support coordination, and maintain high morale.

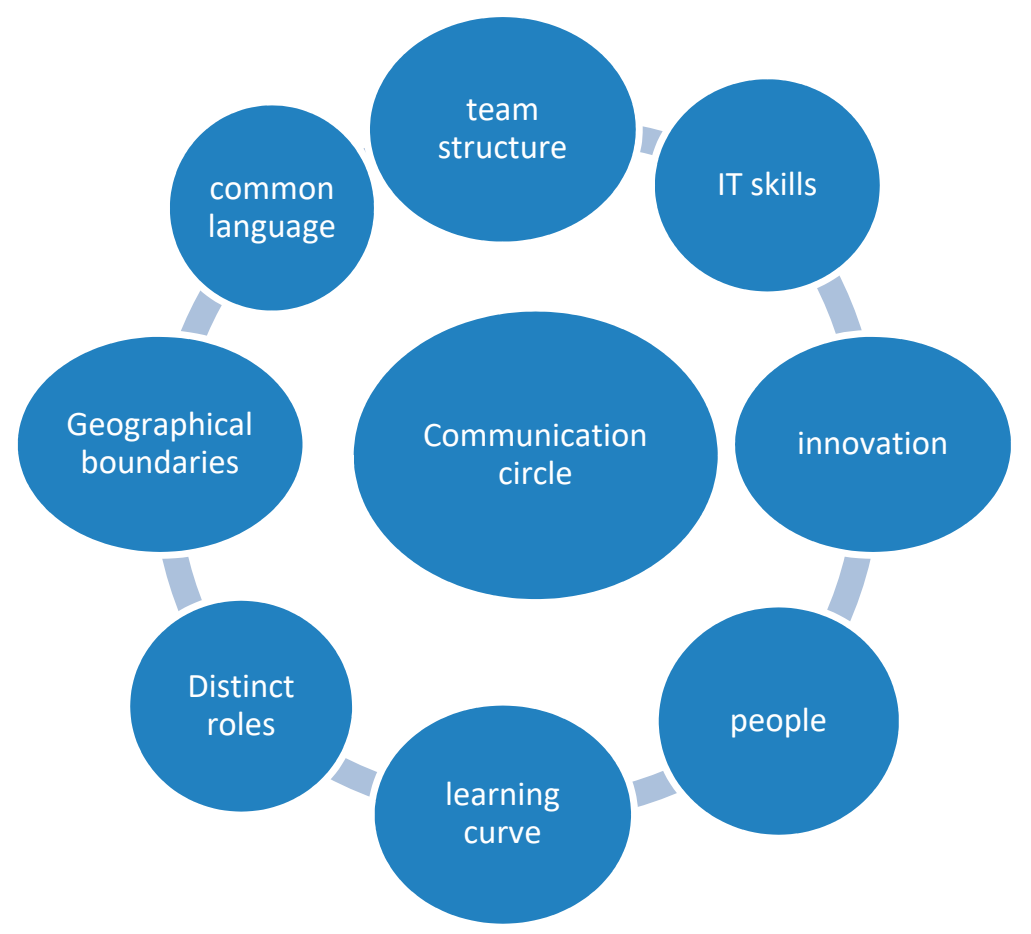

Figure 7. Summarizes the factors that affect communication in construction projects.

\section{Further Discussion}

Research has determined the factors and mechanisms of communication-maximizing principles that ease the way for architects or design professionals to organize, design, and construct teams for successful projects in the Lebanese construction industry.

The study was based on the supposition that, with the increase in division and assessment of the tectonic, architectural design has increasingly become a communicative organizational process, in which a variety of participants are concerned with different viewpoints and expertise. For that reason, the achievement of the project depends a lot upon how the team is organized, and well thought of, by having strategies supporting facilitators and reducing inhibitors to communication.

Through the use of seven different case studies, the chance to investigate how different teams advanced design and construction in architecture projects was one of the most motivating aspects of this study. There is no definite, single, or unique appropriate project delivery system. Moreover, communication relationships differ, depending the team's organization and setting. A common issue in all of the studied projects is that participants need to have the ability to work, with anybody, at any time, and on any project, and the existing boundary of less communication is improved by the offered 
values. These values or principles do not only improve the assigned jobs at a micro stage, together with design and construction tasks, but they also facilitate the whole team build-up and share an intention of high quality design that infuse through all levels of association. Eventually, the organizational system and information technology unite to form the communication circle with its principles.

\subsection{Limitations}

The major limitation of this study appear to be the denial of regional identity, as a result of globalization and internationalism, and the limited creativity enjoyed by the architect, since the design phase is fragmented into sub-divisions were several architects are involved.

The complexity of the industry makes it a hard job to generalize one definite design model to follow, but it also reflects the need to acquire the fundamentals of an adaptable communication structure for better project design and implementation.

The study reveals the possibility of additional variables, because it is limited to definite phases and scale. The architecture projects analyzed and studied were limited to medium or to small size projects, as the study had to be done in only two years, and it had to cover both, design and construction phases. Therefore, further factors might be discovered if larger scale projects are undertaken.

Funding: This research received no external funding

Conflicts of Interest: The authors declare no conflict of interest.

\section{Appendix A. Questionnaire Sample}

\section{A-The Scale and Nature of Project}

1- What is the cost of project involved in? more than 5 million dollars

2- What is the scale of project handled? large size project

3- Does the scale of project affect the organization structure (design team structuring)? If yes, in what sense?

Yes, the organization structure is highly affected by the scale of the project since the tasks and the number of expertise increase with the increase in scale and therefore the project becomes more complex and difficult to manage.

4- Does the scale of project affect the number of participants involved? If yes, draw the relation between project's scale and members.

Yes, as mentioned before, the increase in project's scale automatically increases the number of participants involved.

5- What is the kind of the project achieved?

commercial

6- How long is the project's complete process of design drawings (design and construction)? more than 3 years

7- How long is the implementation (construction phase) of the project?

more than 5 years

8- What phases of the project were you involved in?
a- Design drawings
b- Construction drawings
c- implementation and completion
$\mathrm{a} \& \mathrm{~b}$ a\&c $\mathrm{b} \& \mathrm{c}$
$\mathrm{a}, \mathrm{b} \& \mathrm{c}$

9- Was the client involved in any phase? What phase: 
Yes, his involvement was throughout the whole process.

B-Members involved in the communication process

10- What is the number of members involved in the design phase?

More than 10 members.

11- What is the number of members involved in the construction phase?

team of more than 10 engineers involved in construction and on site implementation.

12- Are the members involved specialists in specific phases of the project?

Yes, especially in the phases related to hotel details, retailing issues and cinema construction.

13- Do the members involved come from different cultural backgrounds?

No, it was limited to local parties.

14- How does the culture of parties affect the communication process?

NA

15- Are the members involved located in the same region or country?

In this case study, the members were located in the same region.

16- How does the geographical location affect the communication process?

The members were located in the same region, therefore they communicate continuously with each other at different intervals of the project in hand. This made the nature of communication an $\mathrm{f} 2 \mathrm{f}$ process and digital one too.

17- To what extent are you involved in the communication process?

$100 \%$

C-The Structure of Organization (Communication model)

18- What is the structure of organization?
a- hierarchal
b- linear
c- traditional
d- center oriented

Other, specify

19- How are tasks assigned?

Tasks are assigned according to the work breakdown structure of the project.

20- Who manages the whole process? Project manager

21- Are you the sender or receiver?

Both the sender and receiver

22- Does the nature of project affect the organization structure? How?

Yes, since this project is a commercial one, the organization structure took a linear arrangement.

D-The nature of communication

23- Why do you communicate in architecture firms in Lebanon?
a- when you do not know: the need for expertise
b- when you do not want to do something
c- when you do not have time
d- when you do not have the resources
e- $\quad$ when you want to enhance your skills 
you may circle more than one condition

24- What is the nature of collaboration maintained?
a- $\quad$ Face 2 face communication-Oral
b- Technological and IT integration
c- Both

E-Factors that affect communication in architecture project management

25- List the major factors that enhanced communication in this project?

Flexible project manager

Clear objectives

Direct operation Managing all phases in parallel

26- List the major factors that inhibited communication in this project?

Overlapping roles

Excessive interference of client

Unfamiliar technology How do you collaborate in an F2F design construction environment?

27- Who are the members involved?

Suppliers, sub consultants, project design director, design architects, architecture teams and engineering staff, draftsmen.

28- How is the team structure maintained?

All involved members refer to the project manager.

29- How are tasks assigned?

Tasks are assigned by the project manager.

30- Who manages the process?

The design consultant in collaboration with the project manager.

31- Is this system efficient? Does it make communication between participants easy and clear?

The system needs a more developed structure of organization that handles well the collaboration between participants and enhances the flow of information.

32- List 3 of the obstacles you faced using the F2F communication system:
a- $\quad$ Loss of information
b- $\quad$ Still needed digital communication to deliver all data
c- Not official since there isn't any documented files.

How do you collaborate in a digital design construction environment?

33- Who are the members involved?

Suppliers, sub consultants, design director, design architect, project coordinator, architecture team and engineering staff.

34- What means of digital communication is being used?
a- $\quad$ fax
b- telephone
c- internet/email
d- intranet
e- $\quad$ web based software

35- Is this system efficient? Does it make communication between participants easy and clear? 
a-Yes b-No

36- Is the database of the web-based software placed locally?

a-Yes b-No

37- Is the communication affected by different time zone?

a-Yes b-No

1. No difference in time.

38- List 3 of the obstacles you faced using the digital communication system:
a- $\quad$ Error in receiving emails
b- Disconnection of network
c- Client's interference in every exchange of digital documents

39- How long have you been involved in the digital communication system?

6 years and above

E-Project delivery system

40- What is the project delivery system maintained?
a- sequential
b- integrated

Please draw a diagram that illustrates the process of communication between all parties involved in the design and construction phases of the architecture project?

Project delivery system

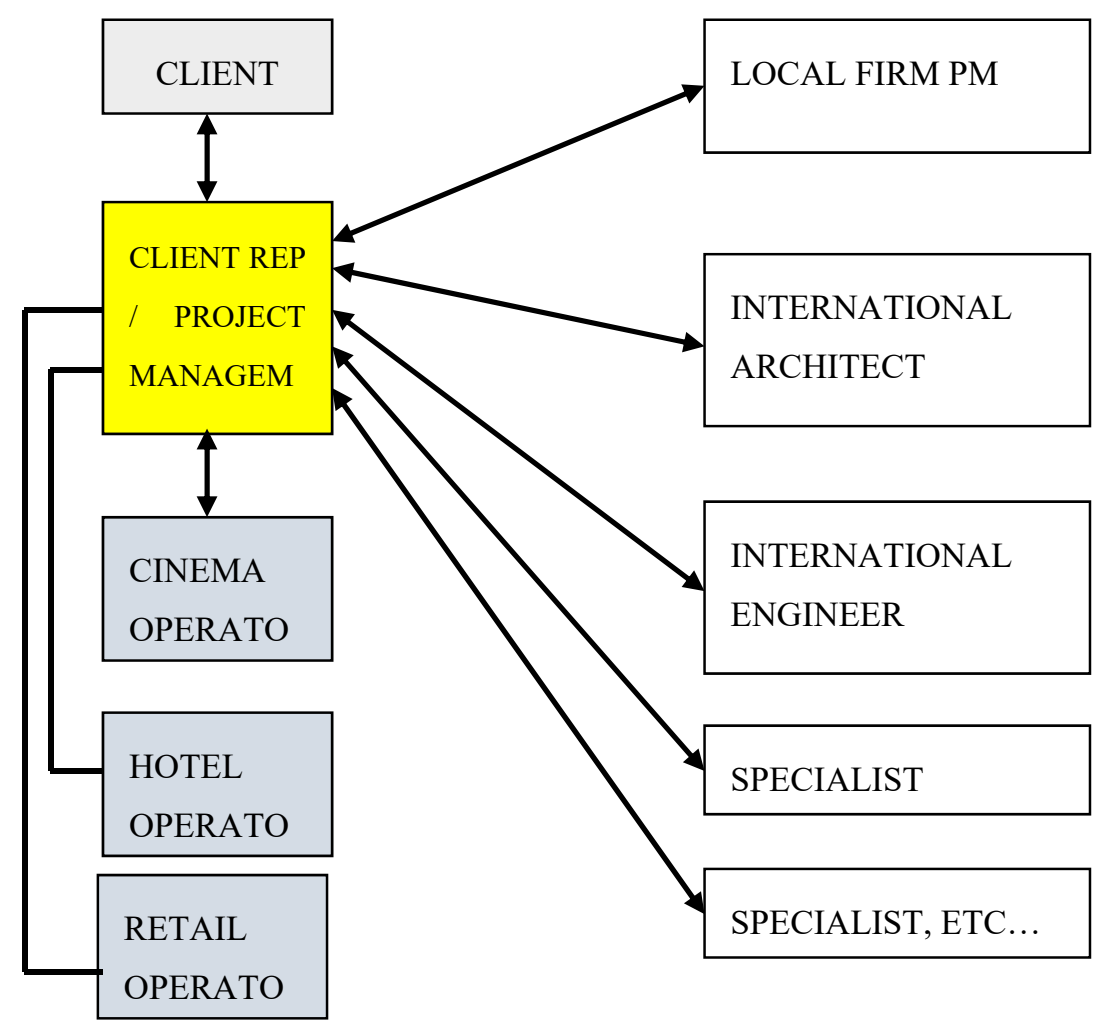




\section{References}

1. Blyth, K.; Lewis, J.; Kaka, A. Developing a framework for a standardized works programme for building projects. Constr. Innov. 2004, 4, 193. [CrossRef]

2. Chan, A. Key performance indicators for measuring construction success. Benchmark. Int. J. 2004, 11, $203-221$. [CrossRef]

3. Kog, Y.C.; Loh, P.K. Critical Success Factors for Different Components of Construction Projects. J. Constr. Eng. Manag. 2012, 138, 520-528. [CrossRef]

4. Cohen, J. Statistical Power Analysis for the Behavioral Sciences, 2nd ed.; Routledge: Abingdon, UK, 2013.

5. Cole, R. Building environmental assessment methods: Assessing construction practices. Constr. Manag. Econ. 2000, 18, 949-957. [CrossRef]

6. Gadde, L.E.; Dubois, A. Partnering in the construction industry-Problems and opportunities. J. Purch. Supply Manag. 2010, 16, 254-263. [CrossRef]

7. Emmitt, S.; Otter, A. Exploring effectiveness of team communication. Eng. Constr. Archit. Manag. 2007, 14, 408-419.

8. Eriksson, P.E.; Westerberg, M. Effects of cooperative procurement procedures on construction project performance: A conceptual framework. Int. J. Proj. Manag. 2011, 29, 197-208. [CrossRef]

9. Eriksson, P.E. Exploration and exploitation in project-based organizations: Development and diffusion of knowledge at different organizational levels in construction companies. Int. J. Proj. Manag. 2013, 31, 333-341. [CrossRef]

10. Foster, D.; Jonker, J. Stakeholder relationships: The dialogue of engagement. Corp. Gov. Int. J. Bus. Soc. 2005, 5, 51-57. [CrossRef]

11. Harty, C. Implementing innovation in construction: Contexts, relative boundedness and actor-network theory. Constr. Manag. Econ. 2008, 26, 1029-1041. [CrossRef]

12. Higgin, G.; Jessop, N. Communication in the Building Industry; Tavistock Publications: London, UK, 2001.

13. Hughes, S.W.; Tippett, D.D.; Thomas, W.K. Measuring Project Success in the Construction Industry. Eng. Manag. J. 2004, 16, 31-37. [CrossRef]

14. Iyer, K.; Jha, K. Factors affecting cost performance: Evidence from Indian construction projects. Int. J. Proj. Manag. 2005, 23, 283-295. [CrossRef]

15. Jeng, T.S. Towards a Process-Centric, asynchronous collaborative design environment. In Proceedings of the Fifth Conference on Computer Aided Architectural Design Research in Asia, Singapore, 18-19 May 2000; pp. 15-24.

16. Zavadskas, E.K.; Turskis, Z.; Tamošaitiene, J. Risk assessment of construction projects. J. Civ. Eng. Manag. 2010, 16, 33-46. [CrossRef]

17. Kerzner, H. Project Management: A Systems Approach to Planning, Scheduling and Controlling, 9th ed.; Wiley: New York, NY, USA, 2006.

18. Ling, Y.Y.; Lau, B.S.Y. A case study on the management of the development of a large-scale power plant project in East Asia based on design-build arrangement. Int. J. Proj. Manag. 2002, 20, 413-423. [CrossRef]

19. Lee, S. Challenges in Building Design and the Construction Industry: The Future of Design and Construction in the Internet Age. Comput. Sci. 2001, 2105, 225-236.

20. Leung, M.Y.; Ng, S.T.; Cheung, S.O. Measuring construction project participant satisfaction. Constr. Manag. Econ. 2004, 22, 319. [CrossRef]

21. Manley, K. Implementation of innovation by manufacturers subcontracting to construction projects; Engineering. Constr. Archit. Manag. 2008, 15, 230-245.

22. Mansfield, N.R.; Ugwu, O.O.; Doran, T. Causes of delay and cost overruns in Nigerian construction projects. Int. J. Proj. Manag. 2004, 12, 254-260. [CrossRef]

23. Matsushima, S. Collaboration in Architectural Design: An IT Perspective. Ph.D. Thesis, Harvard Design School, Cambridge, MA, USA, 2003.

24. Maher, M.L.; Simoff, S.J.; Cicognani, A. Understanding Virtual Design Studios; Springer: Berlin, Germany, 2012.

25. Meng, X. Assessment framework for construction supply chain relationships: Development and evaluation. Int. J. Proj. Manag. 2010, 28, 695-707. [CrossRef]

26. Mezher, T.; Nasrallah, W.; Alameddine, A. The management of technological innovation in Lebanese industry. Int. J. Arab Cult. Manag. Sustain. Dev. 2008, 1, 5-22. [CrossRef] 
27. Molenaar, K.; Javernick-Will, A.; Bastias, G.A.; Meredith, A. Construction Project Peer Reviews as an Early Indicator of Project Success. J. Manag. Eng. 2013, 29, 327-333. [CrossRef]

28. Pilanawithana, N.M.; Sandanayake, Y.G. Positioning the facilities manager's role throughout the building lifecycle. J. Facil. Manag. 2017, 15, 376-392. [CrossRef]

29. Ng, S.T.; Rose, T.M.; Mak, M.; Chen, S.E. Problematic issues associated with project partnering: The contractor perspective. Int. J. Proj. Manag. 2002, 20, 437-449. [CrossRef]

30. Phua, F.; Rowlinson, S. How important is cooperation to construction project success? A grounded empirical quantification. Eng. Constr. Archit. Manag. 2004, 11, 45-54. [CrossRef]

31. Rahmawati, Y.; Anwar, N.; Utomo, C. A Concept of Successful Collaborative Design towards Sustainability of Project Development. Int. J. Soc. Hum. Sci. Eng. 2013, 7, 1042-1048.

32. Rwamamara, R. Planning the Healthy Construction Workplace through Risk Assessment and Design Methods. Ph.D. Thesis, Civil, Mining, and Environmental Engineering, Luleå University of Technology, Luleå, Sweden, 2007.

33. Rutten, M.; Doree, A.; Halman, J. Innovation and inter-organizational cooperation: a synthesis of literature. Constr. Innov. 2009, 9, 285-297. [CrossRef]

34. Serpell, A.; Ferrada, X.; Rubio, N.L. Fostering the effective usage of risk management in construction. J. Civ. Eng. Manag. 2017, 23, 858-867. [CrossRef]

35. Shen, L.Y.; Tam, V. Implementation of environmental manage-ment in the Hong Kong construction industry. Int. J. Proj. Manag. 2002, 20, 535-543. [CrossRef]

36. Tai, S.; Wang, Y.; Anumba, C.J. A survey on communications in large-scale construction projects in China. Eng. Constr. Archit. Manag. 2009, 16, 136-149. [CrossRef]

37. Thompson, J.D. Social Science Bases of Administrative Theory, 1st ed.; Routledge: New York, NY, USA, 2017.

38. Tseng, S.M. The effects of information technology on knowledge management systems. Expert Syst. Appl. 2008, 35, 150-160. [CrossRef]

39. Serrador, P.; Turner, R. The Relationship between Project Success and Project Efficiency. Int. J. Proj. Manag. 2014, 25, 150-157. [CrossRef]

40. Zwikael, O.; Shimizu, K.; Globerson, S. Cultural differences in project management processes: A field study. Int. J. Proj. Manag. 2005, 23, 454-462. [CrossRef]

(C) 2019 by the author. Licensee MDPI, Basel, Switzerland. This article is an open access article distributed under the terms and conditions of the Creative Commons Attribution (CC BY) license (http://creativecommons.org/licenses/by/4.0/). 